
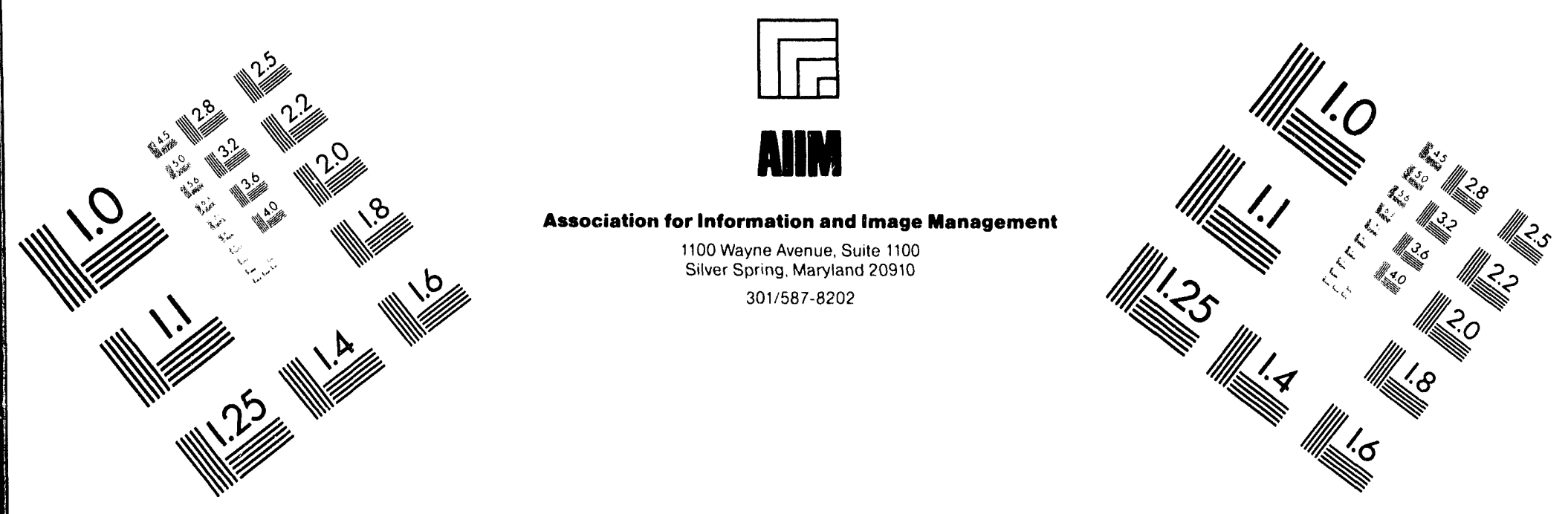

\title{
Centimeter
}

$\left.\right|_{1} ^{1}$

Inches
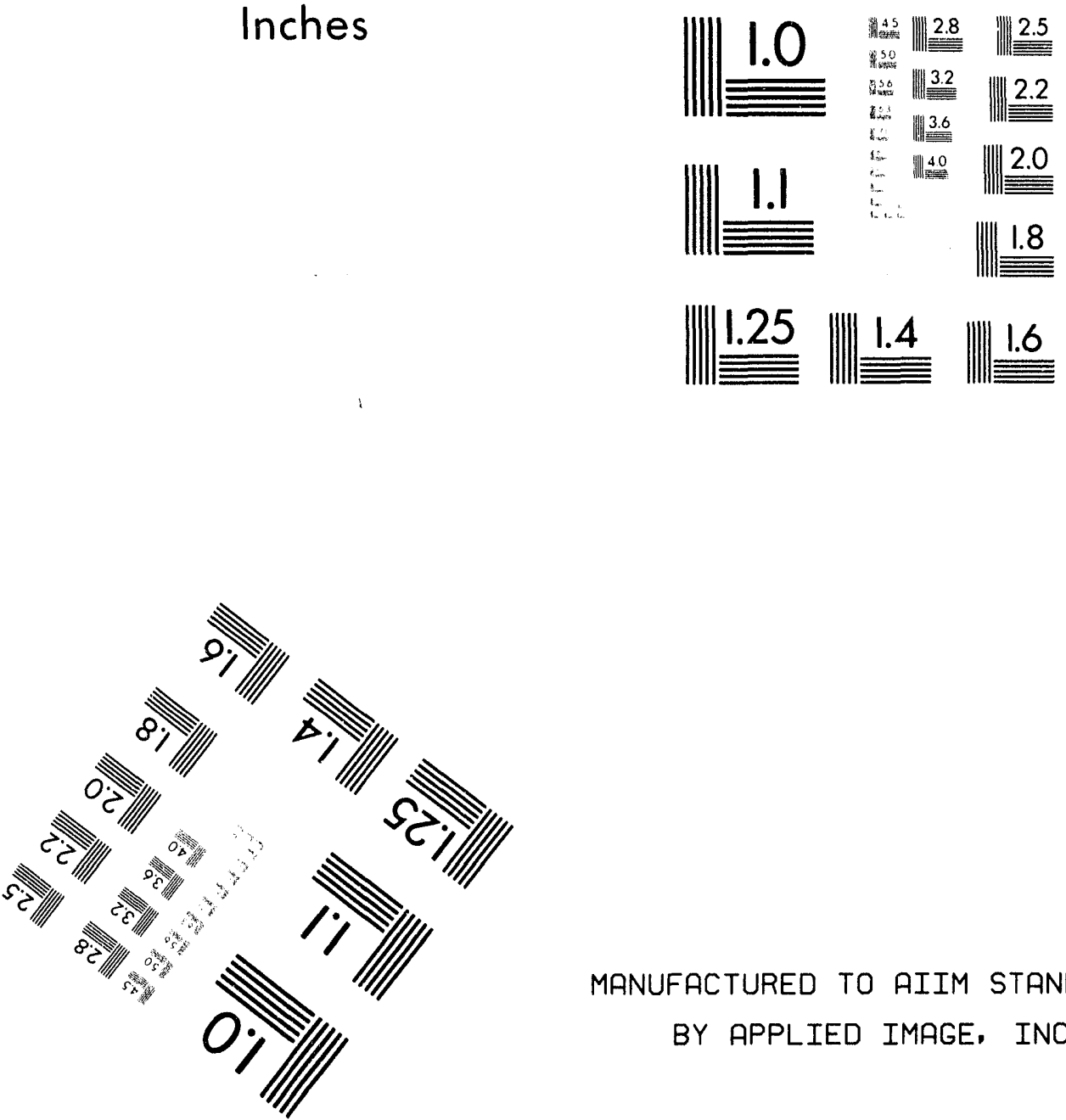

MANUFACTURED TO AIIM STANDARDS

BY APPLIED IMAGE, INC.

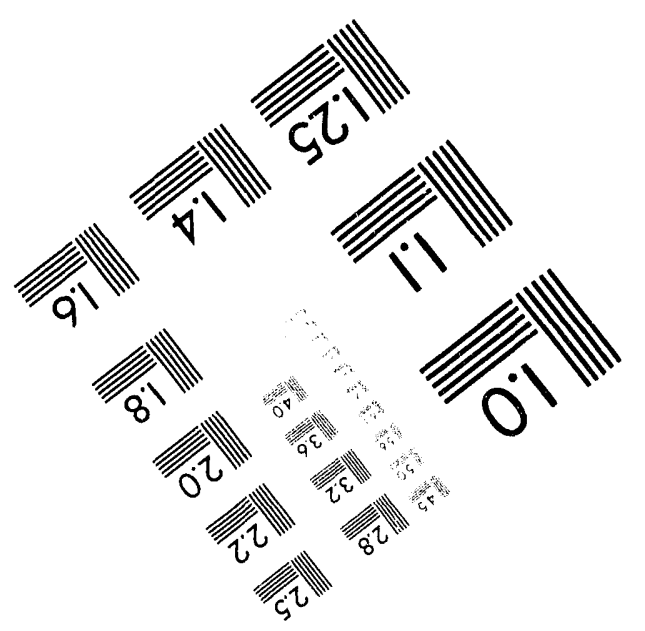




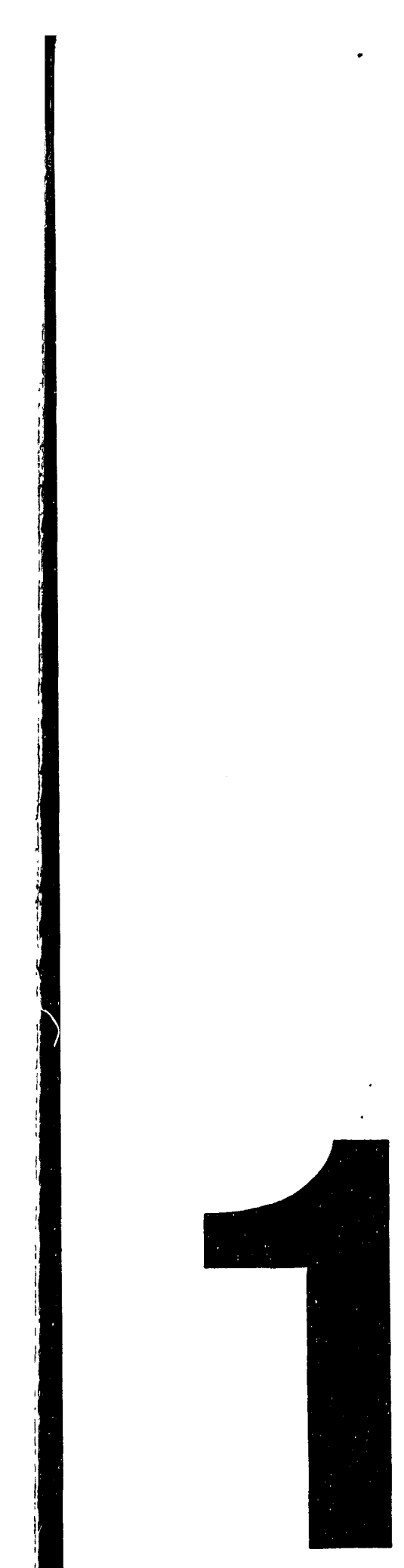




\section{GUIDANCE ON MEETING DOE ORDER REQUIREMENTS FOR TRACEABLE NONDESTRUCTIVE ASSAY MEASUREMENTS}

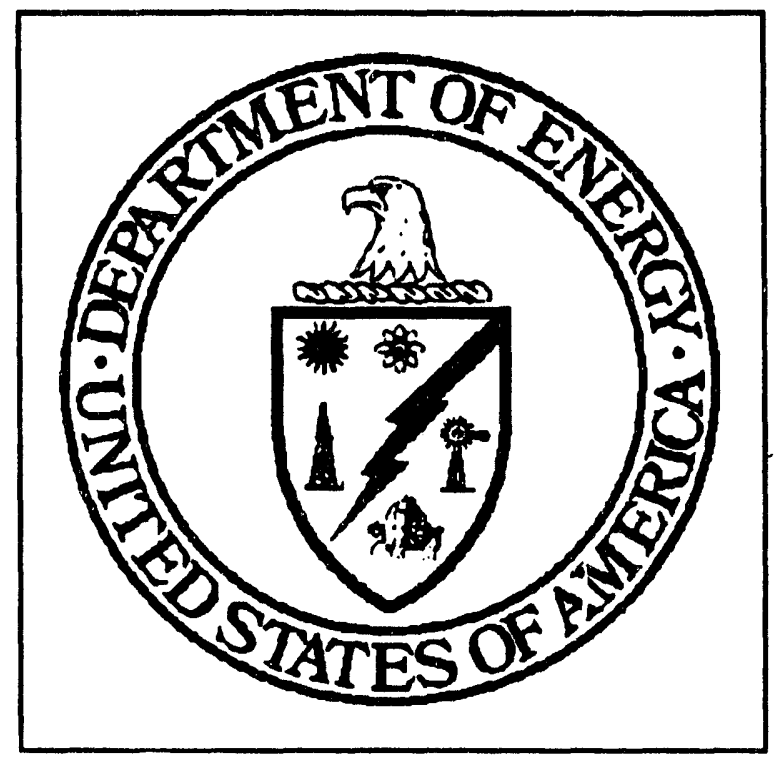

May 1994

Prepared by U.S. Department of Energy New Brunswick Laboratory Argonne, Illinois

For U.S. Department of Energy

Office of Nonproliferation and National Security Office of Security Affairs Office of Safeguards and Security

Policy, Standards, and Analys is Division Materials Control and Accountability Branch 
I. Introduction

Measurement techniques providing values for safeguards accountability purposes must meet requirements of applicable Department of Energy (DOE) Orders and good laboratory practice. Quality control for destructive assay is assured through the use of certified reference materials (CRMs) or working reference materials (WRMs) (see the appendix for definitions), standards which are traceable to the national measurement base. Estabiishing traceability for nondestructive assay (NDA) techniques is not readily accomplished, as there is currently a scarcity of CRMs available for use with NDA techniçues (See Section IV). Existing nuclear CRMs were developed primarily for destructive assay purposes and are not directly suitable for calibrating NDA systems. As the use of NDA continues to increase in the areas of shipper/receiver measurements, inventory confirmation measurements, and movement of nuclear materials from process into storage areas, the need to develop applicable reference materials (RMs) and establish traceability is of vital importance.

This document provides DOE and its contractor facilities guidance to establish traceability to the national measurement base for siteprepared NDA WRMs. Such traceability enhances comparability between different NDA techniques and may enhance the accuracy of assay values within the accepted systematic uncertainty of the technique.

Traceability also provides greater assurance of the accuracy of reported nuclear materials assay and isotopic measurements, increased confidence in the accuracy of records, and increased material loss detection sensitivity.

The guidance and the references contained in this document are recommended approaches and are not intended to be used in determining compliance. This document is not intended to dictate what systems or methods are suitable for a particular process or facility, nor is it intended to be a substitute for the use or development of NDA CRMs. Instead, it is intended to facilitate the institution of better measurement control through improving traceability for site-specific NDA WRMs. Efforts to develop CRMs for NDA measurements will continue within DOE.

Properties of the standards should be representative of the materials to be measured in all characteristics that affect the measurement system. However, it is frequently not possible to provide standards (RMs) for all types of samples to be measured by NDA, to make standards which are absolutely representative for many heterogeneous types of samples and the NDA measurement techniques and instruments used, or to identify all parameters that can affect NDA measurements. The goal. should be to assure that the standards and the material to be measured are consistent in all important characteristics that may affect the NDA measurement. In this context, it should be recognized that standards used on one measurement system may be totally inappropriate for another application or technique. Accordingly, characteristics of standards and materials to be measured should be evaluated for each application or technique. 
Previously issued Office of Safeguards and Security guides, particularly the Measurement Control Guide (March 1993) and the Measurement Improvement $P$ lan (June 1993), provide useful information about measurement systems, measurement capabilities, and documentation of measurement control practices.

\section{The Importance of Traceability}

The purpose of this decument is to facilitate accuracy and precision of NDA measurement through improving the reliability of nuclear materials used for traceability of instrument calibration. Measurement traceability is established by an unbroken linkage, or comparison, of measurements to a nationally accepted reference base. Traceability, for WRMs is, of course, only part of the requirement for a quality WRM.' Additionally, the WRM must be designed and constructed properly, initial destructive or nondestructive measurements must be of sufficient precision and accuracy to provide traceability to the national. measurement base, and the WRM must be used appropriately. Thus, it is imperative that the design, production, and use of the WRM be coordinated from the beginning among all concerned disciplines, including quality assurance personnel, chemists, physicists, material handlers, material packagers, statisticians, and NDA instrument users.

The nuclear material content of a sample is often determined by a relative measurement method; an example of this involves comparing the observed instrument response from an unknown amount of material to the response from standards by means of a functional relationship established through calibration. Factors which can influence instrument response for calibration include: (1) properties of the nuclear material such as isotopic composition, physical and chemical form, density and particle size; (2) properties of the matrix material such as physical and chemical form, density and particle size; (3) vistribution of the nuclear material within the matrix; (4) properties of decay daughters and time since separation; and (5) for NDA, properties of the container such as chemical composition and dimensions.

The calibration of NDA instruments which utilize relative measurement methods may be valid only for measurement of samples that do not differ significantly from the standards in matrix, density, particle size, composition, distribution, and/or container characteristics. In such cases, differences with respect to a property other than nuclear material content, to which the observed response is sensitive, will have an effect on the nuclear material assay results. Differences due to matrix, density, distribution, and container may constitute the most significant sources of systematic uncertainty in some NDA measurements. Significant effort is usually required to identify the sources of

'ASTM Standard C 1128-89, "Standard Guide for Qualification of Measurement Methods by a Laboratory Within the Nuclear Industry, "Annual Book of American Society for Testing and Materials Standards, Vol. 12.01 Nuclear Energy (I), 1992. 
systematic error and to accurately determine the necessary corrections for a particular NDA measurement. NDA WRMs will allow for evaluation of the NDA technique over time at some specified frequency and provide assurance that the system is operating properly. It is also very desirable to perform comparisons with alternate assay techniques; for example, periodic use of destructive measurements can be used to provide additional quality assurance for the measurement system.

In cases where the NDA techniques are not relative measurement methods, the measurements are based on fundamental physical constants such as gamma-ray energies, branching ratios, intensities, and mass attenuation coefficients. Examples of this type of technique include high resolution gamma-ray spectrometry and some neutron counting methods. CRMs or WRMs traceable to the national measurement base for these NDA techniques can be used to assure that the instrument is operating properly and to monitor the NDA technique's performance over time. However, there are still some of the same sources of error potentially present in these measurements; some sources of this type of error include gamma-ray absorption differences from matrix or material origins, $(\alpha, n)$ reactions from matrix materials, and interferences from decay daughters or other nuclear materials.

The total uncertainty associated with any measurement consists of the random and systematic uncertainties for the measurement method. For most measurements, elimination of all systematic uncertainty is not possible since not all sources of systematic uncertainty are known or, at best, only an estimate of the systematic uncertainty is available. When the estimated systemaicic uncertainty is significantly smaller than the estimated random uncertainty of the measurement method, it may not be advisable to correct the measured value using the estimate. If a measurement process is to be meaningful, the data obtained must be both accurate and precise to within agreed limits. How accurate and precise a measurement needs to be depends upon the end-use requirements for the measurement. CRMs or WRMs traceable to the national measurement base are a means of achieving and demonstrating measurement accuracy and precision and for transferring accuracy between and among laboratories using similar measurement methods.

\section{DOE Order Requirements}

When presented with the task of ensuring that NDA measurements meet DOE Order requirements, the first step involves establishing the exact requirements. The portions of DOE Order 5633.3A that address NDA measurements are relatively few to allow flexibility and general application. Applicable order requirements follow.

Section I.1.n. Procedures, techniques, and standards as promulgated by the American Society for Testing and Materials (ASTM) and the American National Standards Institute (ANSI) shall be used, when such standards exist, in developing the bas is for nuclear material control, measurements and measurement control, 
accounting, and statistical methods that are employed by a facility for safeguarding of nuclear material, unless otherwise directed by DOE Orders. Standards issued by the International Atomic Energy Agency and the Nuclear Regulatory Commission (NRC) should also be used when appropriate and when consistent with DOE regulatory goals.

Section 11.4.d.(2).(d). All measurement methods shall be calibrated using standard reference materials (SRMs), CRMs, or secondary standards traceable to the national measurement base, and revalidated as necessary.

Section 11.4.e.(1).(e). Instrumentation shall be calibrated using appropriate standards, when available, or at a minimum, measurement values shall be compared with more accurate measurement systems values on a prescribed basis, with the frequency being defined by demonstrated instrument performance.

Section $11.4 . e .(1) .(f)$. All calibration and working standards used in a measurement control program shall be traceable to the national measurement base through the use of SRMs or CRMs and shall have smaller uncertainties associated with their reference values than the uncertainties of the measurement method in which they are used. Working standards used in a measurement control program shall be representative of the type and composition of the material being measured when the material matrix affects the measured values.

Section 11.4.e.(1).(i). Each facility shall have a documented method qualification program that ensures that a measurement method shall demonstrate acceptable performance before being used for performing accountability measurements. For destructive analysis and NDA of nuclear miterial, this performance shall be demonstrated, at a minimum, once per day that each method is used. For NDA measurement systems where meeting this requirement is impractical or unnecessary, the control measurement frequency shall be at least one of every five measurements, unless otherwise approved by the Manager, DOE Operations Office.

Section 111.5.d. Each facility shall monitor for SNM in all liquid, solid, and gaseous waste streams leaving a material access area in order to ensure that discharge levels remain within acceptable limits, unless a specified deviation is granted. Monitoring instrumentation may be semi-quantitative, provided that the monitors used are capable of detecting gamma/neutron radiation characteristics of the specified material type.

In summary, the Order requires that measurements be made with a measurement system that is calibrated with SRMs, CRMs, or WRMs traceable to a SRM or CRM, when available. The Order refers to ASTM and ANSI standards for further guidance. A list of these ASTM and ANSI standards is provided in the following section. 


\section{Applicable Guidance Standards}

\section{A. ANSI Standards}

ANSI N15.20-75 (R1987, N15.21), "Nondestructive Assay Systems, Guide to Calibrations," American National Standards Institute, Inc., 1430 Broadway, New York, NY 10018 (1987).

ANSI N15.22-87, "Plutonium-Bearing Solids, Calibration Techniques for Calorimetric Assay," American National Standards Institute, Iirc., 1430 Broadway, New York, NY 10018 (1987).

ANSI N15.35-83, "Calibration Material for Nondestructive Assay Systems That Count Passive Gamma Rays, A Guide to Preparing," American National Standards Institute, Inc., 1430 Broadway, New York, NY 10018.

ANSI N15.36-83, "Nondestructive Assay Measurement Control and Assurance," American National Standards Institute, Inc., 1430 Broadway, New York, NY 10018.

ANSI N15.37-81, "Guide to the Automation of Nondestructive Assay Systems for Nuclear Materials Control," American National

Standards Institute, Inc., 1430 Broadway, New York, NY 10018.

B. Annual Book of ASTM Standards, Vol 12.01

(page numbers given are for the 1993 edition)

ASTM Standard C 853-82, "Standard Test Methods for Nondestructive Assay of Special Nuclear Materials Contained in Scrap and Waste," pp. 323 - 331, containing the following procedures:

"Nondestructive Determination of Plutonium in Containers of 4 Liters or Less of Fabrication Waste By Neutron-Coincidence Counting," (Sections 3 to 11);

"Nondestructive Determination of Plutonium in Containers of 1 Liter or Less in Fabrication Scrap By Neutron-Coincidence Counting," (Sections 12 to 19);

"Nondestructive Determination of Plutonium in 55- and 30Gallon Drums of Combustible Fabrication Wastes By NeutronCoincidence Counting," (Sections 20 to 28);

"Nondestructive Analysis of Plutonium in Fabrication Scrap and Waste in Containers of 20 Liters or Less By Segmented Passive Gamma-Ray Scanning," (Sections 29 to 36); and

"Nondestructive Determination of Transuranic Radioisotope Activity in Low-Density Combustible Waste at the $10 \mathrm{nCi} / \mathrm{g}$ Level," (Sections 37 to 44). 
ASTM Standard C 1030-89, "Standard Test Method for Determination of Plutonium Isotopic Composition by Gamma-Ray Spectrometry, " pp. 539 - 545.

ASTM Standard C 1068-91 "Standard Guide for Qualification of Measurement Methods by a Laboratory Within the Nuclear Industry," Pp. 578 - 581 .

This standard provides guidance for selecting, validating, and qualifying measurement methods when qualification is required for a specific program.

ASTM Standard C 1128-89 "Standard Guide for Preparation of Working Reference Materials for Use in the Analys is of Nuclear Fuel Cycle Materials," pp. 627 - 635.

This standard provides guidance for the preparation and characterization of WRMs that are produced by a laboratory for its own use in the analysis of nuclear materials. Guidance is provided for establishing traceability of WRMs to CRMs by a defined characterization process. The guidance provided is generic; it is not specific for a given material or for a specified measurement system.

ASTM Standard C 1133-89, "Standard Test Method for Nondestructive Assay of Special Nuclear Material in Low Density Scrap and Waste by Segmented Passive Gamma-Ray Scanning," pp. 636 - 645.

ASTM Standard C 1207-91, "Standard Test Method for Nondestructive Assay of Plutonium in Scrap and Waste by Passive Neutron Coincidence Counting," pp. 730 - 737.

ASTM Standard C 1215-92, "Standard Guide for Preparing and Interpreting Precision and Bias Statements in Test Methods Standards Used in Nuclear Industry," pp. 744 - 752.

\section{CRMs Currently Available for NDA}

There are currently two NDA nuclear material standards that have CRM status. They are: (1) the New Brunswick Laboratory (NBL) standard NBLCRM-969, for calibration of gamma-ray spectrometric measurement of ${ }^{235} \mathrm{U}$ isotopic abundance of depleted and low-enriched uranium, and (2) the Central Bureau for Nuclear Measurements (CBNM) standard CBNM-NRM-271, for gamma-ray spectrometric measurement of the isotopic abundances of plutonium. NBL is part of the Department of Energy. CBNM was part of the Commission of the European Communities Joint Research Centre in Geel, Belgium, which is now called the Institute for Reference Materials and Measurements (IRMM).

NBL-CRM-969 (also known as EC-NRM-171 and NBS-SRM-969 in the literature) consists of a set of five $\mathrm{U}_{3} \mathrm{O}_{8}$ powders with different ${ }^{235} \mathrm{U}$ isotopic 
abundances, each encased in an aluminum can. The atom percent ${ }^{235} \mathrm{U}$ ranges from 0.3 to 4.5 ; an empty can is also included for use when measuring unknowns. This set of RMs was produced by the National Bureau of Standards (NBS) (now the National Institute of Standards and Technology [NIST]) in cooperation with CBNM and NBL. NBS published a detailed account of the production and certification of NBL-CRM- $969^{2}$. An extremely useful guide for application of these standards to ${ }^{235} \mathrm{U}$ enrichments measurements is al so available $e^{3}$.

CBNM-NRM-271 consists of a set of four samples of sintered plutonium dioxide discs in welded stainless steel containers. The materials are of the following nominal ${ }^{239} \mathrm{Pu}$ isotopic abundances: $93,84,70,61$. Each sample weighs 6.65 grams. The welded containment makes it possible to ship these materials as Type $A$, special form. These RMs were produced by CBNM. There are three sets of CBNM-NRM-271 in the United States: one each at Los Alamos National Laboratory (LANL), Lawrence Livermore National Laboratory (LLNL), and NBL. Information on the use of this reference material has been documented. 4,5

\section{NDA Working Reference Materials}

In the absence of NDA CRMs, NDA WRMs that are traceable to CRMs may be used for calibration of NDA techniques. There are several approaches which may be utilized to establish traceability of the WRMs. For example, one or more samples previously assayed by the NDA system could be assayed by an independent technique. If a CRM is properly used in the calibration of the independent technique, then traceability can be established through an unbroken chain of measurements. The drawback to this approach is that the independent technique is usually a destructive assay method. Consequently, although previous measurements referenced to the assayed sample may be validated by destructive assay, the

"Uranium-235 Isotope Abundance Standard Reference Materials for Gamma Spectrometry Measurements," B.S. Carpenter, J.W. Gramlich, R.R. Greenberg, L.A. Machlan, P. DeBievre, H. L. Eschbach, H. Meyer, J. Van Audenhove, V.E. Connolly, N.M. Trahey, and A.C. Zook; National Bureau of Standards, NBS Special Publication 260-96, 1986, PB-87-108544.

3 "Accurate Determination of the ${ }^{235} \mathrm{U}$ Isotope Abundance by Gamma Sectrometry: A User's Manual for the Cert if ied Reference Material EC-NRM-171/NBS-SRM-969," P. Matussek, Kernforschungszentrum, Germany, Karlsruhe Report KfK 3752, May 1985.

4"Improvement of Isotopic Composition Measurements of Plutonium by the Use of Calibration Samples for Gamma Spectrometry," P. Fettweis, H. Meyer, F. Quik, Nuclear Safequards Technology 1986, Symposium Proceedings, November 10-14, 1986, Vienna, Austria, International Atomic Energy Agency, 1987, pp. 363-374.

5 "Plutonium Isotopic Abundance Measurements on CBNM NRM 271 Analyzed with the FRAM and MGA Codes," R. J. Friar and T. E. Sampson, Los Alamos National Laboratory, LA-12309-MS, May 1992. 
material itself is no longer available to provide traceability for subsequent NDA measurements.

A more lasting approach involves fabricating WRMs by one of the following methods: (1) placing known quantities of special nuclear material (SNM) in fixed positions within a matrix; (2) mixing SNM together with a matrix in some specified manner; or (3) preparing duplicate items with one item destructively analyzed and the other item maintained for NDA. By properly using a CRM for the destructive analysis of the SNM uşed in the fabrication process or in the duplicate items, traceability to the national measurement base can be established.

\section{A. Requirements for NDA WRHs}

When planning the preparation of NDA WRMs, careful consideration should be given to the requirements of the method and the material. 6 Examples of errors that can be made if insufficient planning is done to meet the requirements of the NDA WRM.include: (1) material containers which are different from those in which samples are normally packed (in cases where container material or geometric effects have been demonstrated to cause measurement errors); (2) differences in matrix density between the RM and the samples; (3) using $\mathrm{PuO}_{2}$ with an unknown moisture content for calibration of neutron interrogation systems (in this case composition effects cause errors); or (4) using standards not spanning the practical analysis range of the instrument where feasible.

Examples of other less common but equally important factors that should be assessed include:

For gamma-ray systems, consideration should be given to potential interferericics and to absorption effects both within the SNM material and from matrix materials. Interferences may result from decay daughters, other nuclear materials, or from activation sources (note that $(\alpha, n)$ reactions can also produce cascade gamma-rays). For absorption effects, SNM and matrix distributions and densities of the RM should approximate those of the materials to be measured as closely as possible where feasible and useful. This is frequently evaluated by measuring gamma-ray intensity ratios from the two sources.

For neutron assay systems, consideration should be given to activation sources for additional neutrons such as $(\alpha, n)$ reactions from the standard and to neutron absorbing materials such as hydrogenous components, beryllium, and

"The Preparation of Large Standards for NDA Measurements," S. Guardini and J. K. Sprinkle, Jr., 32nd Annual Meeting Proceedings, Institute of Nuclear Materials Management, Vo1. XX, 1991, Pp. 995 - 997. 
cadmium. Other factors relating to activation/absorption may also be important for active interrogation systems. Examples of these factors include the following:

\author{
Homogeneity (no lumps), \\ Stability (no SNM migration or settling), \\ Absence of hydrogenous materials (for active \\ neutron interrogation), and
}

Similarity of matrix material density.

However, a NDA WRM may be so application-specific that broad generalizations do not hold. For example, a lumpy, heterogeneous molten salt residue may be an appropriate choice as a working standard for a segmented gamma scanner (SGS) measurement. Such a material might be characterized by a method with demonstrated accuracy, such as calorimetry with gamma isotopics and become a WRM that would be defensible in a regulatory sense.

Because materials for many working standards developed at sites will come from process and product streams, potential interferences from impurities must be addressed. For example, systematic errors arising from uncorrected interfering effects, can contribute to the overall uncertainty of a measurement. The following reference is useful regarding (1) measurements of actual industrial materials under industrial conditions and (2) interlaboratory certification of WRMs for NDA:

"Quality Control Provisions Applied in the Preparation and Characterization of Pu-bearing PERLA Standards," $S$. Guardini, G. Guzzi, F. Mousty, S. Baumann, E. Kuhn, P. De Regge, EUR 13038EN, Joint Research Center, Ispra, Italy, 1990 .

B. Examples of the Preparation and Characterization of NDA WRMs

Some specific examples of the preparation and characterization of WRMs for NDA can be found in the following references:

"Design and Fabrication of SGS Plutonium Standards," S. -T. Hsue, S. M. Simmonds, V. L. Longmire, and S. M. Long, Proceedings of the Fourth International Conference on Facility Operations - Safequards Interface, American Nuclear Society, 1991, Pp. $410-413$.

These standards (RMs) consist of high-fired plutonium dioxide dispersed in diatomaceous earth and packaged in double containment, custom-designed cans that are laser welded. These NDA WRMs satisfy the following requirements of the SGS assay technique for plutonium: 
a. The SNM should be uniformly distributed in the standards.

b. The standard should have a diameter such that the gamma-ray transmission through it is reasonable $(0.1<T<0.6)$.

c. The height of the standard containing SNM should be at least ten times the height of the collimator used in. the SGS measurement.

d. The particle size of the SNM should be small so that the self-absorption of the particle is negligible.

The RMs described are in regular use at LANL and Savannah River facilities.

"The Preparation and Characterization of a Plutonium Oxide Reference Material for Non-Destructive Analysis," D. Crossley, A.J. Fudge, J.W.A. Peckett, R.A.P. Wiltshire, and A.J. Wood, Atomic Energy Authority Technology Fuel Services, Harwell Lahoratory, United Kingdom, AEA-FS-00374(H), March 1991.

These RMs are intended for use with passive neutron coincidence counting measurements of plutonium. A set of ten NDA WRMs was prepared to cover the range of 0.1 - 25.0 grams of plutonium. The source material was reactor grade plutonium dioxide, which was chemically purified to remove americium and impurities such as fluorine, beryllium, and boron which could generate additional neutrons by $(\alpha, n)$ reactions. The plutonium content was determined by controlled-potential coulometry which provided measurements traceable to the internationally accepted European Certified reference material EC-201, plutonium metal. The isotopic composition of the plutonium was determined by thermal ionization mass spectrometry which provided measurements traceable to the certified reference material UK-Pu3/92134; measurement of the ${ }^{238} \mathrm{Pu}$ content was performed by $\alpha$-spectrometry. The material was doubly encapsulated in a right circular cylinder of constant diameter with the source material depth varying throughout the range.

"Characterization of Consistent NDA Standards," W.W. Rodenburg, E.F. Novak, and R.J. Seiler, Journal of Nuclear Materials Management, 17, 1988, pp. 713 - 717.

In early 1984, Savannah River Plant engineers identified the need for a new set of plutonium oxide 
RMs. The materials were characterized for several attributes including wattage, grams of plutonium, plutonium concentration, isotopic composition (including ${ }^{241} \mathrm{Am}$ ) and impurities. To cover the range of possible isotopic compositions, five different materials with nominal ${ }^{210} \mathrm{Pu}$ compositions of $3,6,9$, 12 and 15\% were produced. All material preparation was performed at LANL. Each material type was carefully selected for low americium content (less than two years since the separation date) and low impurities, especially uranium and thorium. Characterization was performed at Mound, LANL, and NBL. These materials can be used to calibrate calorimeters, solid isotopic systems, and neutron coincidence counters.

"Design of an Interlaboratory Comparison Standard for NDA Measurement of Scrap and Waste," N.M. Trahey, J.M. Scarborough, and C.D. Bingham, 18th Annual Meeting Proceedings, Institute of Nuclear Materials Management, Vol. VI, No. III 1977, pp. 659 - 662 .

"Preparation of Prototype NDA Reference Materials: A Progress Report," A. M. Voeks and N. M. Trahey, Natjonal Bureau of Standards, NBS Special Publication 582, June 1980, pp. $25-31$.

"Interlaboratory Comparison Program for Nondestructive Assay of Prototype l'ranium Reference Materials," N.M. Trahey, M.M. Smith, A. M. Voeks, and J.T. Bracey, Topical Report NBL-306, New Brunswick Laboiratory, December 1986.

These three publications provide a record of the design, preparation, and evaluation of three prototype RMs for NDA of uranium in scrap and waste. The matrix materials selected were synthetic calcined ash, cellulose fiber, and ion-exchange resin to simulate selected uranium scrap and waste streams which are normally encountered in fabrication or recovery operations. The synthetic calcined ash represented an intermediate density inorganic matrix, while the cellulose fiber and ion-exchange resin were. representative of low-density organic matrices.

The synthetic calcined ash prototype was composed of oxides of silicon; aluminum, iron, zirconium, niobium, calcium, and uranium. The set of synthetic calcined ash prototype RMs was comprised of seven levels of uranium ranging from 0 to $13 \%$ uranium concentration of 93.16\% ${ }^{235} \mathrm{U}$ enrichment. Approximately 950 grams of each uranium concentration level of synthetic calcined 
ash were sealed in specially fabricated cylindrical, polypropylene containers.

The cellulose fiber prototype consisted of uranium absorbed in chromatographic grade fibrous cellulose powder. The set of synthetic cellulose fiber prototype RMs was comprised of six levels of uranium ranging from 0 to $6 \%$ uranium concentration of $93.13 \%$ ${ }^{235} U$ enrichment. A standard $\# 1$ tall, tin-plate can with an oleoresin coating on the inside surface was used to contain approximately 175 grams of each uranium concentration level of synthetic cellulose prototype reference material.

The ion-exchange resin set of synthetic prototype RMs had the same uranium concentration range, percentage ${ }^{235} \mathrm{U}$ enrichment, and container type as the cellulose fiber set. Approximately 250 grams of each uranium concentration level of the synthetic ion-exchange resin prototype reference material was used in each container.

"Design and Fabrication of Segmented-Gamma-Ray-Scanner Plutonium Drum Standards," S.-T. Hsue, S.M. Long and V.L. Longmire, LA-12334-PR, Los Alamos National Laboratory, July 1992, pp. 27-28.

A set of three drums containing one each of $30 \mathrm{~g}, 100 \mathrm{~g}$, or $200 \mathrm{~g}$ of plutonium oxide is being fabricated.

Because of the size of a 55-gallon drum, achieving uniform distribution of the SNM by mixing it in the drum is difficult, if not impossible. Therefore, the approach to be used is to mix the SNM with diatomaceous earth in 4-1iter bottles and to distribute the bottles within the drum. Celotex will be used to fill the voids between bottles, because it has the same density as diatomaceous earth.

"Design and Fabrication of the Uranium Drum Standards," F. Hsue, S.M. Long, S.-T. Hsue, and M.C. Miller, 34th Annual Meeting Proceedings, Institute of Nuclear Materials Management, Vol. XXII, 1993, pp. 940-944.

A set of three uranium drum standards has been fabricated at LANL. This paper discusses a Mote Carlo calculation to optimize the design of the drum standards. The drum standards are prepared using 20 modular 4-liter bottles in each drum. This paper describes fabrication, vertical scanning data to assuring uniform mixing of the uranium and diluent, and consistency measurements made on the standards. 
"Bias Investigation of a 55-Gallon Drum-Sized Segmented

Gamma Scanner," J.R. Hurd, S.M. Long, and T.E. Sampson, 34th Annual Meeting Proceedings, Institute of Nuclear Materials Management, Vo1. XXII, 1993, PP. 675-681.

This paper addresses a series of studies undertaken while fulfilling the measurement requirements of a 55gallon drum-sized SGS to be used at the plutonium facility at LANL. The first investigation concerned effects cause by item not being exactly centered on the measurement table. The remaining studies involved establishing the magnitude of the bias induced by socalled "end effects" as well as by size differences between calibration standards and assay items.

"Accurate, Wide-Range Uranium Enrichment Measurements by Gamma-Ray Spectroscopy," Los Alamos National Laboratory, J. L. Parker and M. Brooks, LA-11277-MS, September 1988.

In early 1985, LANL's Safeguards Assay Group undertook the repackaging and recharacterization for use as working standards, nineteen approximately l-kg lots of uranium oxide. These materials included twelve enrichments ranging from normal to $91 \%$ enriched ${ }^{235} \mathrm{U}$. The lots of oxide had been acquired over a period of about 15 years from several sources. The $1-\mathrm{kg}$ lots. were packaged in poorly characterized cans, and in most cases, there had been only routine-quality analysis of the isotopic ratios and uranium concentration based on a single small sample. By repackaging and recharacterizing these oxides, a valuable set of working standards for use in investigating the limits of gamma-ray enrichment measurements was provided economically.

"Reference Materials for Nondestructive Assay of Special Nuclear Material," J. K. Sprinkle, R. N. Likes, J. L. Parker, and H. A. Smith, LA-9910-MS, LOS Alamos National Laboratory, Vols. 1 and 2, October 1983.

Volume one reports the fabrication of uranium diluted with graphite for use with a SGS. Volume two reports on the fabrication of uranium metal foils used for calibrating passive gamma-ray anal!zers. 
"Quality Control Provisions Applied in the Preparation and Characterization of Pu-bearing PERLA Standards," S.

Guardini, G. Guzzi, F. Mousty, S. Baumann, E. Kuhn, P. De Regge, EUR 13038EN, Jo!nt Research Center, Ispra, Italy, 1990.

Plutonium oxide and mixed uranium/plutonium oxide working standards for neutron coincidence counters are described in this paper. The results of the different quality control checks are presented and discussed. The report is intended for use in conjunction with the PERLA standard certificates which are issued for each type of material considered and provides the user the capability of tracing all analytical data back to primary standards.

"Passive Neutron Waste-Drum, Assay with Improved Accuracy and Sensitivity for Plutonium Using the Add-A-Source Method," H.0. Menlove, Journal of Nuclear Materials Management, Vol. XX, No. 4, July 1992, Pp. 17-26.

A new measurement technique improves the accuracy and sensitivity of the NDA of plutonium scrap and waste. The 200-1iter drum assay system used the classical method of counting passive neutron coincidences, but introduces a small ${ }^{252} \mathrm{Cf}$ source near the external surface of the drum. The drum perturbs the rate at which coincident neutrons from the small source are counted, providing data for corrections related to material matrix and composition. The detectability limit of the system is better than prior systems for actual waste materials.

\section{Examples of Work to Provide Traceability for NDA RMs}

Specific examples of the work required to provide traceability for NDA WRMs follow. The work was done by NBL at the request of the respective Operations Offices with Argonne National LaboratoryWest (ANL-W), Idaho Chemical Processing Plant (ICPP), and Westinghouse Savannah River Company (WSRC).

\section{Argonne West}

ANL $W$ does uranium analysis on glass and dust samples from casting scrap by NDA. Attempts to improve the NDA technique were being made, but destructive assay on the material was needed to provide more accurate, traceable assay information on the materials being analyzed. LANL, in providing assistance to improve the NDA method, performed NDA analyses on the glass and dust samples before they were sent to NBL for destructive assay. NBL provided traceable uranium assay values on three glass and dust samples for inter-comparison 
with the NDA methods to determine if the changes to the NDA technique improved the assay value.

2. Westinghouse Savannah River

WSRC uses NDA measurement systems such as the ${ }^{252} \mathrm{Cf}$ Shuffier, developed by LANL, for accountability measurements. WSRC needed traceability for uranium/aluminum (U/AI) alloy standards being prepared on-site. NBL performed uranium concentration measurements on 120 coredrilled samples of U/AI alloy and uranium isotopic measurements on every fourth sample. The measurements were done using a statistical scheme worked out by WSRC with NBL using CRMs for quality assurance controls. The assays provided traceability for the materials WSRC then used to prepare standards for NDA.

\section{Idaho Chemical Processing Plant}

ICPP needed $\mathrm{UO}_{3}$ standards for use in an active well coincidence counter which it uses for accountability measurements. The standards were fabricated by an Oak Ridge laboratory and sampled for destructive assay to be performed at NBL. NBL developed the statistical sampling scheme with the ICPP personnel. NBL performed uranium concentration and isotopic analyses using CRMs for quality assurance which provided traceability for the NDA standards.

\section{Waste Measurements}

\section{A. ASTM Standards for Waste Measurements}

The area of waste measurements includes many diverse sample types and unique situations which would seem to defy standardization. Nevertheless, those working in this area have begun to establish some common ground by publishing the following ASTM standards.

ASTM Standard C 1133-89, "Standard Test Method for Nondestructive Assay of Special Nuclear Material in Low Density Scrap and Waste by Segmented Passive Gamma-Ray Scanning," ASTM Annual Book of Standards, 1993, Vol. 12.01, pp. $636-645$.

ASTM Standard C 1207-91, "Standard Test Method for Nondestructive Assay of Plutonium in Scrap and Waste by Passive Neutron Coincidence Counting," ASTM Annual Book of Standards, 1993, Vol. 12.01, pp. 730 - 737. 


\section{B. Literature References for Waste Standards}

There are also reports in the literature that can provide some additional insights into the preparation of standards for waste materials.

"Application of Nondestructive Assay Technology in Oak Ridge National Laboratory's Waste Management Program," F. J. Schultz, M. A. Smith, R. W. Brandenburg, B. A. Caylor, D. E. Coffey, D. C. Hensley, L. B. Phoenix, 3ist Annual Meeting Proceedings, Institute of Nuclear Materials Management, Volume XIX, 1990, pp. 944 - 952.

"Measurement of Nuclear Material in Waste," B. H. Armitage, T.W. Packer, M. T. Swinhoe, and D.B. Syme, United Kingdom, Safeguards Development Project Report SRDP-R169, June 1990.

This report concentrates on developments made in the United Kingdom with active neutron interrogation using the californium shuffler and the differential dieaway technique. Means of overcoming matrix effects and problems with fissile material particle size are explored. A summary of the typical performance for passive gamma, passive neutron, and active neutron interrogation is included. Relevant NDA techniques for safeguards have been developed primarily for monitoring the fissile content of well characterized samples or product streams, and not all are suitable or fully developed for the more demanding task of monitoring waste materials of generally unknown composition. In dealing with a drum of unknown composition the methods have individual limitations but also share common problems such as the following: (1) obtaining a reliable source (active interrogation), (2) correcting for the effects of the drum filling material such as inhomogeneities, and (3) correcting for self-shielding in lumps of fissile materials.

"DOE Assay Methods Used for Characterization of ContactHandled Transuranic Waste," F. J. Schultz, J. T. Caldwell, Oak Ridge National Laboratory, ORNL-6485, 1991.

Both NDA and destructive assay methods are discussed. New NDA developments, passive-active neutron crate counter improvements and neutron imaging, are detailed. The areas specifically addressed are assay method physics; applicability to Contact-Handled Transuranic wastes; calibration standards and implementation; operator training requirements and practices; assay procedures; assay precision, bias, and limit of detection; and assay limitation. 


\section{vIII. Measurement Control}

Both DOE Order 5633.3A and the corresponding topical document, Measurement Centrol Guide (March 1993), discuss the gradation of measurement control programs based on the attractiveness level of the materials being measured. Under a graded safeguards system, reduced emphasis is placed on materials which are determined to be less attractive for diversion. In the case of accountability measurements, this is accomplished by enlarging measurement uncertainty goals for unattractive materials such as waste or difficult-to-measure materials which contain small quantities of nuclear material. For waste assay systems, the large inherent uncertainty of the measurement (in some cases over 50 percent) could make the use of primary or secondary standards unnecessary or impractical. Understanding the components of the uncertainties which contribute to the total measurement uncertainty is necessary in making decisions regarding the use of traceable standards for measurement control.

When considering what uncertainties are tolerable for a given stratum or material type or form, the contribution of the uncertainty from the measurement of the material to the total uncertainty of the material balance area (MBA) must also be evaluated. When the uncertainty on the measurement of specific material types or forms of materials is a significant contributor to the total uncertainty for the MBA, then the use of traceable standards for measurement control of measurement methods used for these materials is most likely to be of importance.

For additional information, the following references are recommended:

"Measurement Control: Principles and Practice as Applied to Nondestructive Assay," T. E. Sampson, Los Alamos National Laboratory, LA-12233-MS, December 1991.

This paper discusses the principles and practice of measurement control for NDA instruments. There are a broad range of sample characteristics presented to most NDA instruments. The wide variability in sample types measured by NDA adversely affects the use and applicability of historical error information from instrument stability checks in estimating measurement uncertainties. This paper emphasizes the methods used to perform instrument stability checks and discisses the resulting uncertainty information that can be derived.

"Analysis of NDA Instrument Calibration Data," T. E. Sampson and A. Goldman, Los Alamos National Laboratory, LA-11316-MS, August 1988.

This is a report which is directed especially towards material control and accountability personnel and statisticians who may be responsible for assessing the 
uncertainties and errors involved in NDA measurements. Some of the topics discussed are the types of calibration curves, general types of standards and their applicability to actual measured samples, and data acquisition.

Recommended international target values (TVs) play an important role in identifying measurement accuracy and precision for the use of similar equipment on similar materials. These values have been accepted internationally as goals which are achievable in routine performance of accountancy and verification measurements. Therefore, TVs provide information which may prompt further inquiry into the choice of a measurement method or into the search for additional sources of error when a facility's stated precision and accuracy for the method exceed those in the TV tables. However, these TVs are for routine performance of measurements, and it would be inappropriate to use TVs to determine the uncertainties which should be associated with working standards or targeted for calibration of instruments or materials used as standards. The uncertainties associated with working standards or instrument calibration should typically be a factor of ten better than routine measurements, if achievable. In practice, a factor of three is often used to minimize the effect of calibration error. The most recent compilation of TVs is the following:

"1993 International Target Values for Uncertainty Components in Fissile Isotope and Element Accountancy for the Effective Safeguarding of Nuclear Materials," International Atomic Energy Agency, Vienna, Austria, STR-294, Rev. 0, October 1993.

The first International Target Values (ITVs) for some NDA methods which are in this IAEA working paper have been published in condensed form in the January 1994 issue of the Journal of Nuclear Materials Management. These ITVs for NDA measurement methods will also be added to update the list already issued for destructive assay measurement methods in the DOE Measurement Improvement Plan (June 1993).

\section{ACKNOWLEDGMENTS}

New Brunswick Laboratory thanks the following reviewers for their helpful comments and contributions during the preparation of this document: James Crabtree and David Crawford, DOE Headquarters; Austin Prindle, LLL; and Willie Hsue, Robert Marshall and Thomas Sampson, LANL. Gail Van Ryn, DOE Headquarters, provided editorial and formatting assistance. 


\section{APPENDIX .}

Definitions of terms utilized in this document, taken from the "Standard Guide for Preparation of Working Reference Materials for Use in the Analys is of Nuclear Fuel Cycle Materials," are as follows.

Certified Reference Material (CRH) -- a reference material with one or more property values that are certified by a technically valid procedure, accompanied by or traceable to a certificate or other documentation that is issued by a certifying body. A certifying body is a technically competent body (organization or firm, public or private) that issues a reference material certificate. ${ }^{p}$ Such an organization could be the National Institute of Standards and Technology which produces standard reference materials or the New Brunswick Laboratory which produces nuclear CRMs. A reference material certificate is a document certifying one or more property values for a certified reference material, stating that the necessary procedures have been carried out to establish their validity. ${ }^{10}$

Reference Material (RM) -- a material or substance, one or more properties of which are sufficiently well-established to be used for the calibration of an apparatus, the assessment of a measurement method, or assigning values to materials." A reference material may also be referred to in this guide as a standard, such as calibration standard or control standard.

Horking Reference Material (WRM) -- a RM usually prepared by a single laboratory for its own use as a caltbration standard, as a control standard, or for the qualification of a measurement method."

${ }^{7}$ ASTM Standard C 1128-89, "Standard Guide for Preparation of Working Reference Materials for Use in the Analys is of Nuclear Fuel Cycle Materials," Pp. 627-635.

8 "Terms and Definitions Used in Connection With Reference Materials," ISO Guide 30, Bureau International de Métrologie Légale, Paris, France, 1981.

${ }^{9}$ Ibid.

${ }^{10}$ Ibid.

${ }^{11}$ Ibid.

12 ASTM Standard C 1068, "Standard Guide for Qualification of Measurement Methods by a Laboratory Within the Nuclear Industry," pp. 578-581. 

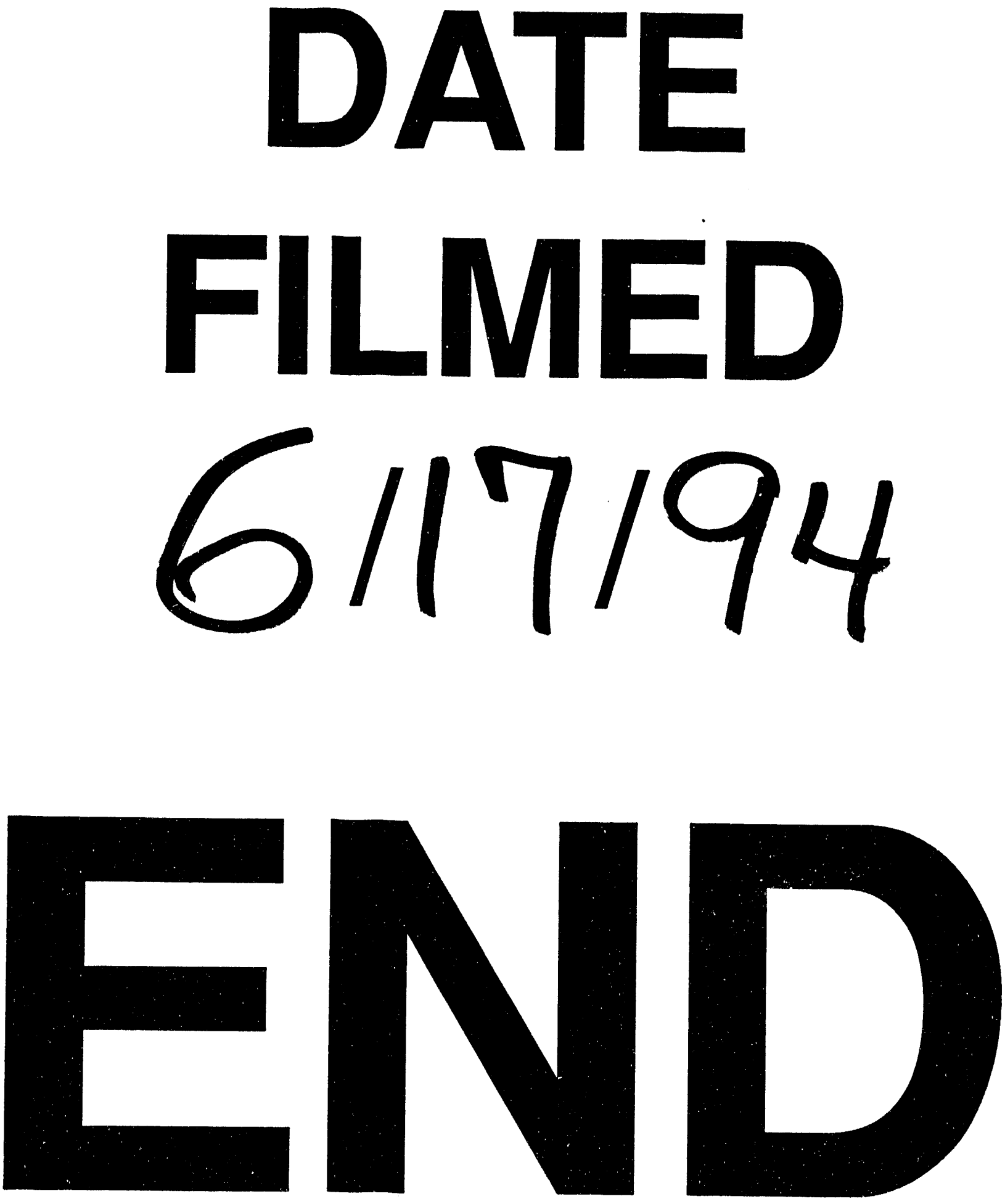
